\title{
Effects of Microstructure and Loading Parameters on Fatigue Crack Propagation Rates in AF2-1DA-6
}

\author{
J. Mason", J. Lemsky ${ }^{* *}$, T. Stuhldreher" and D. Furrer ${ }^{* *}$ \\ *Aerospace and Mechanical Engineering \\ University of Notre Dame \\ 365 Fitzpatrick Hall \\ Notre Dame, IN 46556 \\ ** Ladish Co., Inc. \\ 5481 S. Packard Ave. \\ Cudahy, WI 53110
}

\begin{abstract}
Fatigue crack growth is examined in AF2-1DA-6 over a wide spectrum of growth rates from $10^{-8}$ to $10^{-6} \mathrm{~m} /$ cycle for two mcan stress values ( $R=0.7$ and 0.05 ) and two frequencies (10 and 2 $\mathrm{Hz}$ ) at $649^{\circ} \mathrm{C}$. The effects of one processing parameter, the cooling rate from the solution heat treatment, on Paris law growth rates is examined. In addition, the effects of changes in grain size on the same parameters are examined. No effect of cooling rate from solution heat treatment or of grain size on Paris law crack growth is seen for high $\mathrm{R}$ ratio tests at $10 \mathrm{~Hz}$. However, low $\mathbf{R}$ ratio tests at lower frequency, $2 \mathrm{~Hz}$, indicate that crack growth rates can vary with microstructure. Namely, crack growth rates are higher for a slow cooling rate of $34^{\circ} \mathrm{C} / \mathrm{min}$ for both the ASTM $10 \mathrm{r} / 2$ and 6 average grain sizes. The effect is more dramatic for the smaller grain size. Crack growth rates in that material, i.e. AF2-1DA-6 cooled at the slow rate with a grain size of ASTM $101 / 2$, exhibited the highest growth rate of all when $\mathrm{R}=0.05$ and the sinusoidal load frequency was $2 \mathrm{~Hz}$. Some implications of these results on forging of such alloys are discussed.
\end{abstract}

\section{Introduction}

The forging of aerospace components such as turbine disks or airframe components has increased in sophistication over the last few years. It is now possible to a control desired material properties as well as final shape with a great degree of accuracy. Process modeling using the finite element method (FEM) has been the biggest contributor to these recent advancements.(1) FEM can be used to predict material behavior during forging processes as long as characteristics of materials, tools and processes are well known beforehand. Without good material characterization, the complex, coupled thermo-mechanical deformation of the material cannot be accurately predicted and all accuracy is lost. Prediction of the material deformation during the process is only one of the goals of forging modeling using FEM---prediction of the properties of the completed component is a goal, as well. With good metallurgical models of material response, grain size and strength of the forged component can also be predicted.(1) Therefore, it is important to develop sophisticated material models for use in FEM models of forging.

Typically, in forging, customers specify the desired mechanical properties for a rotating part such as a turbine disk to be manufactured. The forging engineer then determines whether the particular part can be manufactured and estimates the cost and time of that manufacture, if possible. Since the materials used in such aerospace applications are often made of expensive elements, material is not to be wasted and therefore the margin for error is minimal if it exists at all. The answers must be accurate. It is not possible to produce such an accurate response to the customer's request without an accurate data base of material properties, without experienced modeling engineers or without proven process models that can predict the time, cost and feasibility of producing the requested component with the grain size needed for the mechanical properties specified. Clearly, the data base of material properties should include information characterizing the effect of forging upon all important material properties, and the engineer should have a good understanding of what factors in the process affect each mechanical property most.

It is known, for example, that forging strain and cooling rates are critical in determining the final mechanical properties of a forging.(2) These parameters control the grain size for the final material and consequently can have an effect upon the yield strength and ductility of the finished product. However, while higher cooling rates may improve the strength of the material, they may also have detrimental effects on the fatiguc resistance. Until recently, little information about the effects of cooling rate upon the fatigue properties of the material has been incorporated into the design and modeling of forgings. Such information is of significant value to the aerospace engine industry where damage tolerant design---design based on the growth of cracks or flaws assumed to exist in the component---is common. Further sophistication in the modeling of the forging of aerospace components can be achieved if the effects of grain size and cooling rate on the fatigue properties of a forging material can be measured. However, the measurement of fatigue properties of aerospace forging materials can be a costly undertaking. There are many alloys used in a plethora of components exposed to a wide range of operating environments. For each material the fatigue response over a range of microstructures and environments may need to be evaluated leading to large testing programs and lengthy testing times. On the other hand, gathered data can be invaluable in producing customer specified properties and may be used in multiple models reducing the average cost. It is, therefore, important that the effects of forging process parameters upon fatigue crack growth resistance be measured and utilized for future FEM models of forge processing.

In this study, the fatigue crack propagation rate is measured in a turbine disk material that has been exposed to a range of cooling 
rates. The desired effect is to imitate the forging process and to gather data that can be used in the modeling of forging of these materials. Microstructure is known to have an effect upon the fatigue crack growth rate in P/M U720 at high temperatures.(3) This investigation intends to determine if similar effects are seen in the P/M alloy AF2-1DA-6.

\section{Experimental Procedure}

Fatigue crack propagation rate tests were performed following ASTM 647 as described below. The purpose of the tests was to reproduce the characteristic crack growth curve, $\mathrm{da} / \mathrm{dn}$ vs. $\Delta \mathrm{K}$, for each material. Following the collection of the data, a Paris law (4) relationship of the form,

$$
\frac{d a}{d n}=C \Delta K^{m}
$$

was fit to the curve in the Paris Law regime giving the values of the material constants $C$ and $m$ for the material and microstructure tested. The materials were tested in several conditions as described below.

\section{Materials}

The material used for this investigation was P/M alloy AF21DA-6, that was isothermally forged, cut into sized blanks, and heat treated to specific thermal profiles prior to machining of compact tension specimens and program fatigue crack growth testing. The nominal chemistry for AF2-1DA-6 is shown below:

Table I: Nominal Composition for alloy AF2-1DA-6 (wt \%)

\begin{tabular}{|c|c|c|c|c|c|c|c|c|c|}
\hline C & Cr & Co & Mo & Ti & Al & B & W & Ni & Solvus \\
\hline 0.04 & 11.6 & 10.0 & 2.7 & 2.8 & 4.6 & 0.015 & 6.5 & Bal & $1195^{\circ} \mathrm{C}$ \\
\hline
\end{tabular}

Specimens were heat treated to two distinct grain size groups; a coarse grain ASTM 6 and a fine grain ASTM $101 / 2$. Within each grain size group, specimens were heat treated to establish distinct cooling profiles. Figure 1 is a schematic representation of the program heat treatments for both the fine and coarse grain specimen groups.

The grain size was established by an initial high temperature cycle: the coarse grain material was obtained by heating above the $\gamma$ ' solvus, while the fine grain size was obtained by heating near-solvus. After establishing the grain size, specimens of both coarse and fine grain groups were re-treated at a lower $1149^{\circ} \mathrm{C}$ temperature and cooled in a controlled manner for distinct $\gamma^{\prime}$ morphology generation. Then, ageing was carricd out at $760^{\circ} \mathrm{C}$.
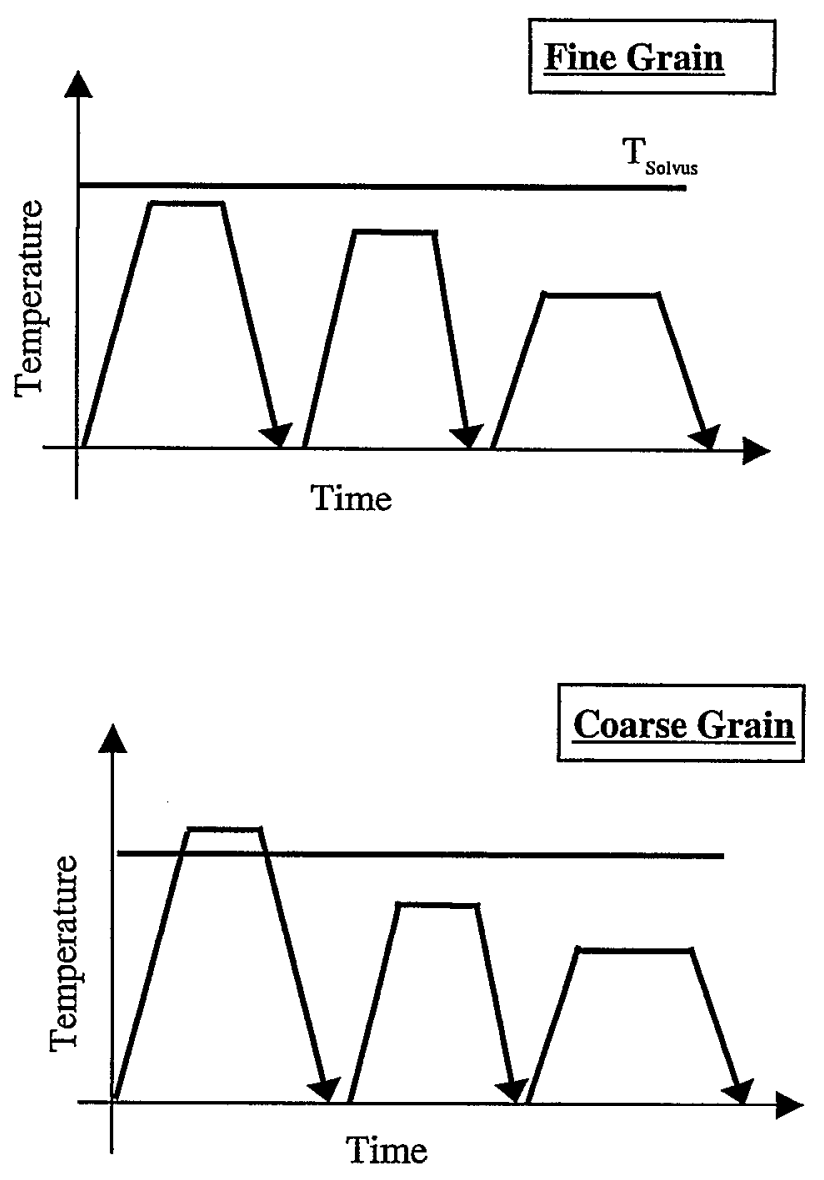

Figure 1. Schematics of heat treatments applied to AF2-1DA-6

The heat treatment cycles given advanced nickel-base superalloys, such as alloy AF2-1DA-6, has a marked influence on gamma prime size, distribution and morphology. Supersolvus processed material resulted in very fine, uniformly distributed primary $\gamma$ ' upon reheating to the second subsolvus solution temperature. Cooling from this temperature resulted in very fine secondary $\gamma^{\prime}$ precipitates between the primary $\gamma^{\prime}$ particles at fast cooling rates (Figures 2a). At slower cooling rates, (Figures $2 \mathrm{~b}$, $2 \mathrm{c}$ ), significant primary $\gamma^{\prime}$ coarsening is observed with greatly reduced content of secondary $\gamma^{\prime}$. The slowest cooled, coarse grain samples resulted in $\gamma^{\prime}$ particles which coarsened to a size which resulted in a morphology change from spherical to cuboidal due to the misfit strains in this alloy.

The fine grain material resulted in distinctly different $\gamma^{\prime}$

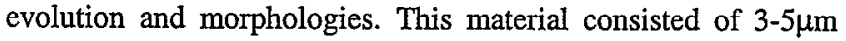
primary $\gamma^{\prime}$ particles which were spaced at distances approximate to the grain size. The secondary $\gamma^{\prime}$ that formed in this material after the second solution cooling cycle is shown in Figures $3 a$ and 3b. Fast cooling resulted in very fine spherical precipitates, while slow cooling resulted in a degeneration to a butterfly precipitate morphology. 


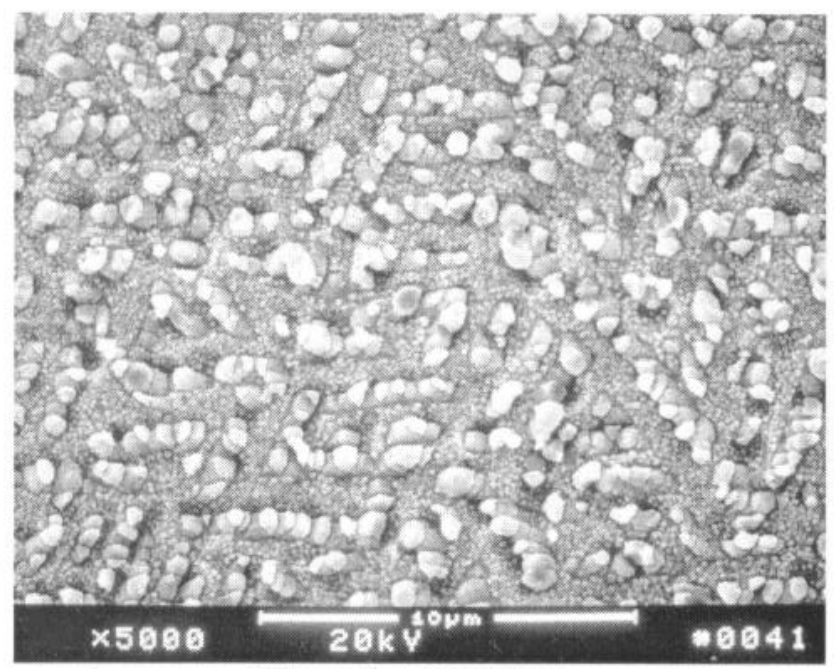

Figure $2 \mathrm{a}-315^{\circ} \mathrm{C} / \mathrm{min}$

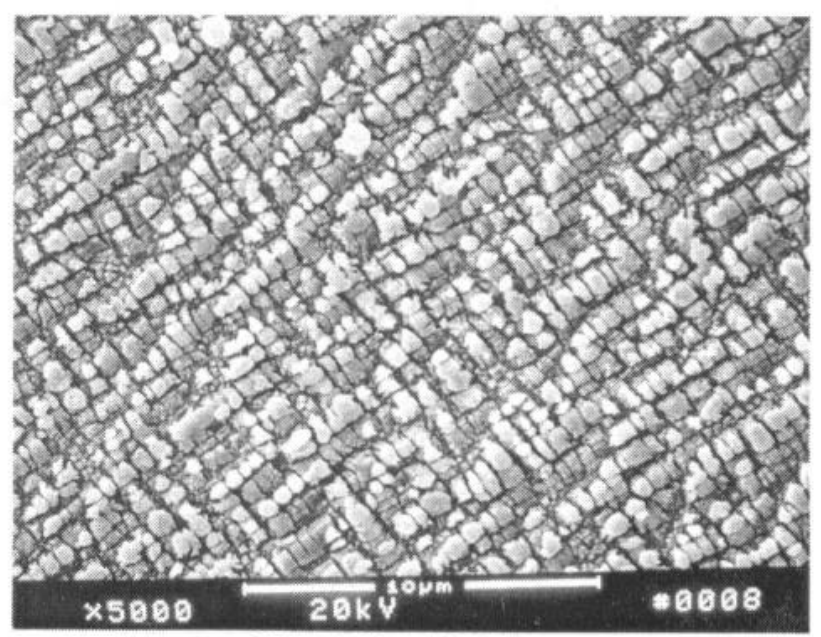

Figure $2 \mathrm{~b}-100^{\circ} \mathrm{C} / \mathrm{min}$

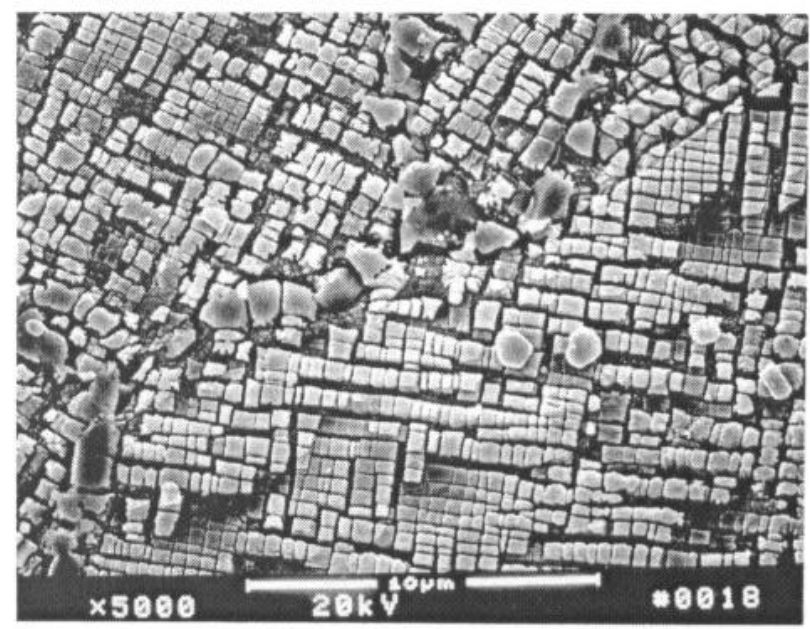

Figure $2 \mathrm{c}-34^{\circ} \mathrm{C} / \mathrm{min}$

Figure 2: SEM microstructures of $\Upsilon^{\prime}$ ' particles after coarse grain heat treat processing

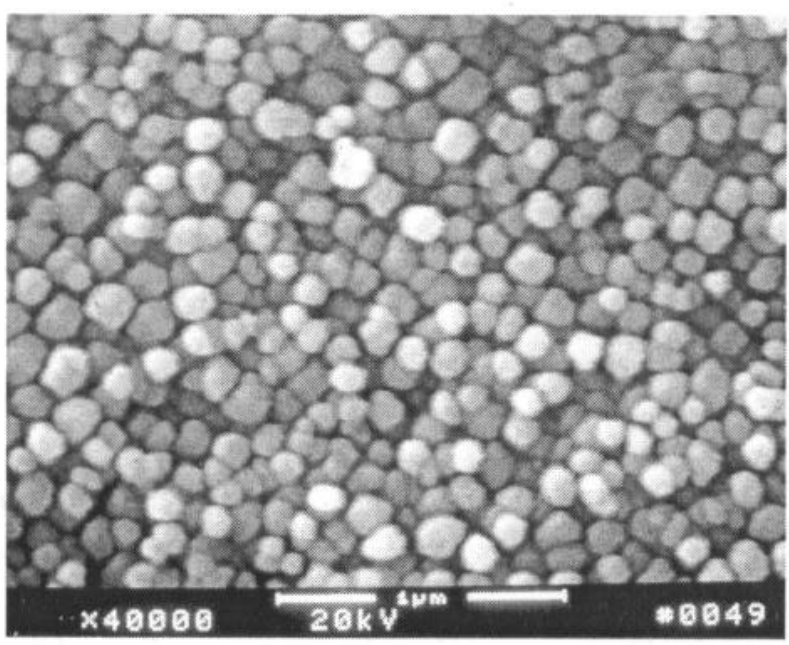

Figure $3 \mathrm{a}-315^{\circ} \mathrm{C} / \mathrm{min}$

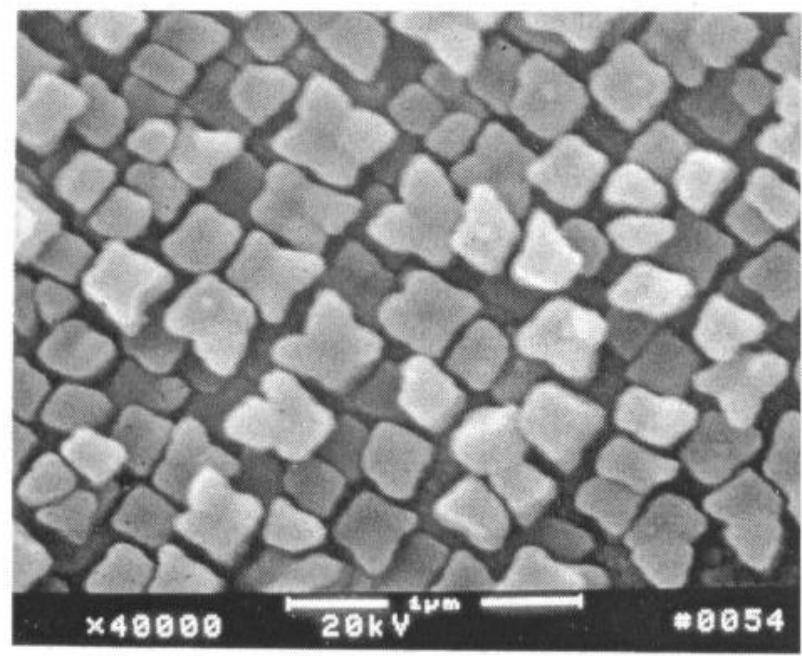

Figure $3 b-100^{\circ} \mathrm{C} / \mathrm{min}$

Figure 3: SEM microstructures of secondary $\Upsilon$ ' particles after fine grain heat treat processing 


\section{Fatigue Crack Propagation Tests}

Fatigue crack propagation tests were performed following the guidelines of ASTM Standard E 647 (5) for crack growth rates from $10^{-8}$ to $10^{-6} \mathrm{~m} /$ cycle using a compact tension specimen. A personal computer is employed to control the stress intensity factor range at the crack tip directly. This is achieved through measurement of the load on the specimen and the crack length in the specimen in real time during the test. These two measurements are then used to calculate the stress intensity factor range using a known solution for the stress intensity factor and the geometry of the specimen. Measurements of the specimen size are taken and entered at the beginning of the test; typical specimen dimensions are given Figure 4. Crack length is measured using the electrical potential drop method.(5) In this method a constant current of 3 Amp is passed through the specimen, entering at point $A$ and exiting at point $B$ in Figure 4, through wires spot-welded to the specimen surface. As the crack length increases the path of the current from point A to point B increases and the resistance to the current increases accordingly. Because of this increase in current path length and resistance, the voltage across points $\mathrm{C}$ and $\mathrm{D}$ increases as well. Through a careful calibration performed at Notrc Dame, the change in voltage can be correlated with the change in crack length. Thus, the voltage across points $C$ and $D$ is measured automatically and is converted into a crack length. Any thermocouple effects due to the difference between the voltage measurement wires and the specimen were removed by current switching. That is, the polarity of current supply was automatically, periodically, switched so that current alternately entered from point $B$ then point $A$. The voltage for each polarity was measured and the two measurements were compared to each other. Any difference in magnitude was removed by manual adjustment of the amplifier and by computer averaging in a redundant system. Tests were carried out in laboratory room air (rclative humidity, 20-50\%) at $649^{\circ} \mathrm{C}\left( \pm 3{ }^{\circ} \mathrm{C}\right.$ ) with a sinusoidal load frequency of $10 \mathrm{~Hz}$ or 2 $\mathrm{Hz}$. The temperature of the specimen was monitored throughout the experiments by a thermocouple spot welded directly to the side of the specimen.

As per the standard, each test began with $1 \mathrm{~mm}$ of crack growth at a growth rate of about $10^{-9} \mathrm{~m} /$ cyclc. Thus, the effects of crack initiation and of the notch tip geometry were minimized. By the end of $1 \mathrm{~mm}$ of growth the crack growth rate stabilized to a constant value. Then the crack growth rate was decreased using an automated load shedding procedure. The equation for load shedding developed by Saxena et. al. (6) was used in this procedure,

$$
\Delta K=\Delta K_{o} e^{c\left(a-a_{o}\right)}
$$

where $\Delta \mathrm{K}=\mathrm{K}_{\max }-\mathrm{K}_{\min }$ is the nominal stress intensity range, $a$ is the instantaneous crack length, $a_{0}$ is an initial crack length, $\Delta K_{0}$ is the initial stress intensity range and $c$ is a constant. The intial crack length was taken to be the crack length acheived after the preliminary $1 \mathrm{~mm}$ of growth away from the notch tip. A value of $-0.10 \mathrm{~mm}^{-1}$ was used for $c$. This value is slightly more negative than the value recommended in ASTM E-647, $-0.08 \mathrm{~mm}^{-1}$. However, it is noted in the ASTM standard that more negative values of $c$ can be used depending upon the load ratio, test material and environment. Here, verification of the obtained curves was established by increasing $\Delta \mathrm{K}$ from a value near threshold with $\mathrm{c}=0.10 \mathrm{~mm}^{-1}$. Both increasing and decreasing curves were coincident. Crack growth rates are presented in the following section in terms of the nominal stress intensity range which was computed for the compact tension specimen as per ASTM E-399.(7)

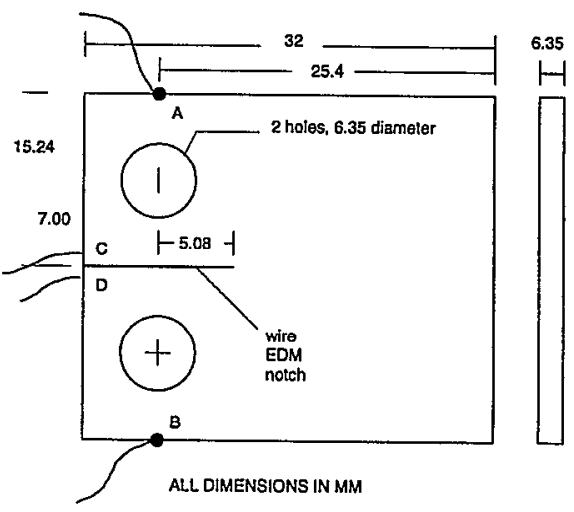

Figure 4. Compact tension, C(T), specimen used in these studies.

The upper range of crack growth rates was investigated. Typically, a stress intensity factor range $20 \%$ below the initial $\Delta K$ in the load shedding procedure, i.e. $0.8 \Delta \mathrm{K}_{0}$, was chosen as a starting point, then the stress intensity factor range was increased using equation (2) with a positive value for $c$. Some of the data for the previous load shedding procedure was reproduced for growth rates slightly below $10^{-9} \mathrm{~m} /$ cycle and then new data was generated for growth rates above $10^{-9} \mathrm{~m} /$ cycle. The overlapping data provided confirmation of the accuracy of the tests. Once confirmation of the lower growth rate data was obtained, the specimen was sacrificed as the higher growth rate data was obtained. The crack was allowed to continue growing until the specimen failed.

TABLE II. Fit parameters for fatigue crack propagation rate data of AF2-1DA-6 for two grain sizes at several different cooling rates from the solution heat treatment.

\begin{tabular}{|c|c|c|c|c|}
\hline $\begin{array}{c}\text { Grain Size } \\
\text { (avg.) } \\
\text { ASTM }\end{array}$ & $\begin{array}{c}\text { Cooling } \\
\text { Rate } \\
{ }^{\circ} \mathrm{C} / \mathrm{min}\end{array}$ & $m$ & $\begin{array}{c}\text { Exponent } \\
\text { e Constant } \\
\mathrm{C}\left(\times 10^{-12}\right)\end{array}$ & $\begin{array}{c}\Delta \mathrm{K}_{\text {th }} \\
M p a \sqrt{m}\end{array}$ \\
\hline 10.5 & 315 & 2.86 & 2.70 & 5.60 \\
\hline 10.5 & 180 & 2.71 & 3.88 & 5.38 \\
\hline 10.5 & 100 & 2.37 & 9.51 & 5.49 \\
\hline 10.5 & 55 & 2.47 & 6.86 & 5.18 \\
\hline 10.5 & 34 & 2.35 & 10.12 & 4.62 \\
\hline 6 & 315 & 2.85 & 2.06 & 5.49 \\
\hline 6 & 180 & 2.92 & 1.79 & 5.49 \\
\hline 6 & 55 & 2.52 & 5.06 & 4.13 \\
\hline 6 & 34 & 2.61 & 4.93 & 3.90 \\
\hline
\end{tabular}

Tests were performed in this study at two $\mathrm{R}$ ratios, $\mathrm{R}=0.7$ and 0.05 where

$R=\frac{K_{\min }}{K_{\max }}$ 
The high $\mathrm{R}$ ratio was initially chosen to minimize the effects of crack closure near the threshold stress intensity range. However, the second round of tests was performed at $R=0.05$ to better match the loading in typical applications for this material and to better match standard testing procedures in the superalloy industry.

\section{Experimental Results and Discussion}

Tests on the AF2-1DA- 6 material at $\mathrm{R}=0.7$ with sinusoidal loading at a frequency of $10 \mathrm{~Hz}$ revealed little variation in the Paris law crack growth with microstructure or processing parameters. As seen in Figure 5 and Table I, the fatigue crack propagation rates in all materials are very similar in the Paris law regime regardless of the grain size or the cooling rate from solution heat treatment. All of the curves fall within in a tight band of uncertainty. Fits of the Paris law for fatigue crack growth, equation (1), to the data resulted in the values for the emperical constants, $C$ and $m$, given in Table I. Regardless of grain size, the exponent, $m$, falls in the range from 2.35 to 2.92 and the multiplicative constant, $C$, falls in the range from $1.79 \times 10^{-12}$ to $10.12 \times 10^{-12}$. The average value of the exponent, determining the slope of the Paris law regime in the figures, is 2.63 with all values falling within $10 \%$ of the average.

Threshold measurements are tabulated in Table I. These values range from $3.90 \mathrm{MPa} \mathrm{m} \mathrm{m}^{1 / 2}$ to $5.60 \mathrm{Mpa} \mathrm{m}$. Mcasurcment between duplicate tests did show some scatter. The exact reason for the scatter is not known at this time. Threshold measurements can be sensitive to numerous factors including microstructure, mean stress and environment, and the mechanisms leading to crack arrest---and the subsequent measurement of threshold under load shedding conditions such as these---which can be statistical in nature. That is, the precise cause of the threshold value may depend upon stochastic variables and therefore the measured value may vary in a stochastic fashion. To be sure, more investigation of the threshold mechanisms is needed through the use of further fatigue crack propagation tests and microscopy of the cracked material when growth rates are very low, i.e. near threshold. In the interest of saving time and due to limited resources for this project, such investigations were not performed here.

TABLE III. Fit parameters for fatigue crack propagation rate data of AF2-1DA-6 for two grain sizes at several different cooling rates from the solution heat trcatment.

\begin{tabular}{|c|c|c|c|}
\hline $\begin{array}{c}\text { Grain Size } \\
\text { (avg.) } \\
\text { ASTM }\end{array}$ & $\begin{array}{c}\text { Cooling Rate } \\
{ }^{\circ} \mathrm{C} / \mathrm{min}\end{array}$ & Exponent & $\begin{array}{c}\text { Multiplicative } \\
\text { Constant } \\
\left(\times 10^{-12}\right)\end{array}$ \\
\hline 10.5 & 315 & 2.77 & 8.33 \\
\hline 10.5 & 100 & 3.33 & 5.81 \\
\hline 10.5 & 34 & 2.93 & 26.7 \\
\hline \hline 6 & 315 & 2.86 & 13.1 \\
\hline 6 & 100 & 2.76 & 19.0 \\
\hline 6 & 34 & 2.83 & 24.1 \\
\hline
\end{tabular}

Keeping in mind that the measurements of $\Delta \mathrm{K}_{\mathrm{th}}$ should be considered preliminary due to the scatter between tests and the incomplete information about the mechanisms of crack arrest in these tests, one might make some cursory observations about the results. First, by examining the results shown in Figure 5 it is possible to surmise that the materials cooled at $55^{\circ} \mathrm{C} / \mathrm{min}$ and 34 ${ }^{\circ} \mathrm{C} / \mathrm{min}$ have lower threshold values than those cooled at higher rates. In fact, further testing may show that the highest threshold may be achieved by the highest cooling rate. Decreasing the cooling rate seems to decrease $\Delta \mathrm{K}_{\mathrm{th}}$ as seen in Table I.

Tests were also performed at lower frequency and lower $\mathrm{R}$ ratio to further investigate the effects of grain size and cooling rate on FCGR in AF2-1DA-6 material. The coarse grain material tested in these conditions (Figure 6) appears to show a slightly slower FCGR as compared to the fine grain samples.

Tests at lower frequency and lower $\mathrm{R}$ ratio revealed that a cooling rate of $34^{\circ} \mathrm{C} / \mathrm{min}$ can result in Paris Law crack growth rates significantly higher than that for materials with higher cooling rate under the same loading conditions. The results of the testing are presented in Figure 6 and Table II where data for tests on AF2-1DA-6 with two grain sizes are presented. It is easy to see that the crack growth rate in the material with a grain size of ASTM $101 / 2$ cooled at $34^{\circ} \mathrm{C} / \mathrm{min}$ is about three times higher than that in all the materials cooled at 100 or $315^{\circ} \mathrm{C} / \mathrm{min}$. The fatigue crack growth rate in this same material is also about 1.7 times higher than the crack growth rate in the material with a grain size of ASTM 6 cooled at $34^{\circ} \mathrm{C} / \mathrm{min}$.

Fitting of the Paris law to the data resulted in the values given in Table II. The exponent for all materials range from 2.76 to 2.97 , with an average value of 2.85 , in good agreement with the tests at $10 \mathrm{~Hz}$ and $\mathrm{R}=0.7$. The results are roughly of the same slope at both frequencies of loading.

\section{Conclusions}

Fatigue crack propagation rate tests were performed on AF21DA-6 for various cooling rates from the solution heat treatment temperature and for two different grain sizes. Growth rates over a wide spectrum were measured. As expected a region of growth governed by the Paris law was observed for a domain of stress intensity factor ranges, $\Delta \mathrm{K}$. In the high frequency tests, for lower values of $\Delta \mathrm{K}$, a threshold stress intensity factor range was observed, $\Delta \mathrm{K}_{\mathrm{th}}$, below which long-crack growth rates were vanishingly small or zero. For higher values of $\Delta K$, a maximum stress intensity factor range was observed above which immediate failure of the specimen could be expected.

At $R=0.7$ and a loading frequency of $10 \mathrm{~Hz}$, fatigue crack growth rates in the Paris law regime for AF2-1DA-6 were insensitive to changes in the cooling rate from the solution heat treatment, but thcy were also insensitive to changes in grain size from ASTM 6 to 10.5 . However, it was found that the threshold stress intensity factor for long-crack growth rate quite possibly was sensitive to cooling rates during processing and that higher cooling rates lead to the more desirable higher threshold stress intensity factor range, $\Delta \mathbf{K}_{\mathrm{th}}$.

It is not surprising that Paris law governed growth was not sensitive to changes in the processing parameters for the higher frequency of loading reported here. Changes in cooling rate will lead to changes in precipitate microstructure as seen in Figures 2 and 3, and it has long been known that Paris law growth is 
usually insensitive to changes in microstructure except for special values of frequency and special environmental conditions.(8)

It appears, however, that for low frequencies on the order of $2 \mathrm{~Hz}$ and low $\mathrm{R}$ ratios special conditions exist where Paris law growth is a function of microstructure, especially for materials tested at $649^{\circ} \mathrm{C}$. In previous work, it has been observed that P/M U720 exhibited a change in crack growth rate for different processing parameters. Likewise, AF2-1DA-6 as tested here demonstrated a dependence of Paris law crack growth rate upon processing parameters. Namely, for the lowest cooling rate, $34^{\circ} \mathrm{C} / \mathrm{min}$, the crack growth rates were significantly higher in both the material with a grain size of 6 and the material with a grain size of 10 . These growth rates were higher than the same materials cooled at much higher rates. The worst case was the material with a grain size of 10 cooled at $34^{\circ} \mathrm{C} / \mathrm{min}$ which had the highest crack growth rate of all. Materials cooled at lower higher cooling rates had lower crack growth rates. These crack growth rates were very similar to the crack growth rates observed in tests at $10 \mathrm{~Hz}$ as can be seen in Tables II and III.

Of interest is the hehavior of the materials cooled at moderate cooling rates, $100^{\circ} \mathrm{C} / \mathrm{min}$. For a grain size of 10 , a moderate cooling rate resulted in crack growth similar to the lowest cooling rate, for the same grain size. However, for a grain size of 6 , the moderate cooling rate resulted in crack growth similar to the highest cooling rate.

It is not precisely clear why these materials exhibit a dependence of Paris law crack growth rate upon microstructure at low frequency and low $\mathrm{R}$ ratio, but is certainly worth noting to the metallurgist and manufacturing engineer. The mechanism must account for the difference in behavior of materials cooled at 100 $\mathrm{C} / \mathrm{min}$ for the two grain sizes tested. At present, no definitive mechanism can be identified, however it appears that the slowest cooling rates lead to the worst properties in terms of high cycle fatigue crack growth response for these testing conditions.

\section{References}

1. T. Furman and R. Shankar, Advanced Materials and Processes 154, (9) (1998) 45-46

2. D. Furrer, Advanced Materials and Processes, 155, (3) (1999) 33-36

3. P.C. Paris, M.P. Gomey and W.P. Anderson, The Trend in Engineering, 13, (1961) 9-16

4. H. Hattori, M. Takekawa, D. Furrer, and R.J. Noel, Superalloys 1996, Kissinger et al. Eds..TMS Pubs, (1996) 705-711

5. ASTM Annual Book of Standards, E 647-95, Vol. 3.01, (1995) 578-614

6. A. Saxena, S.J. Hudak, Jr., J.K. Donald and D.W. Schmidt, J. Testing and Evaluation, 6, (1978) 167

7. ASTM Annual Book of Standards, E 399-90, Vol. 3.01 (1995) $412-442$

8. R.O. Ritchie, in the Encyclopedia of Materials Science and Engineering M.B. Bever, ed. Pergamon Press, Oxford and New York, 3 (1986) 1650-1661 


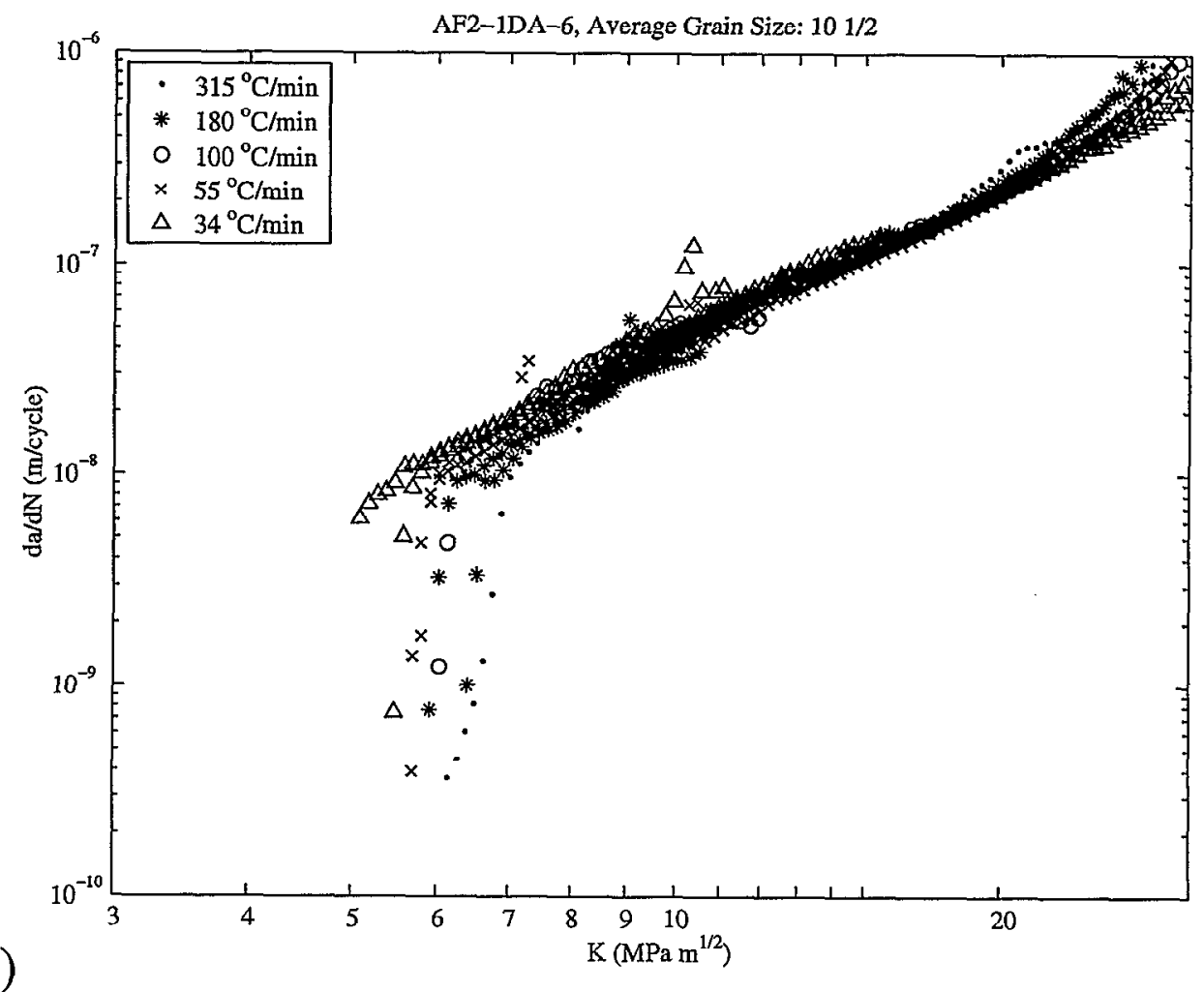

(a)

(b)

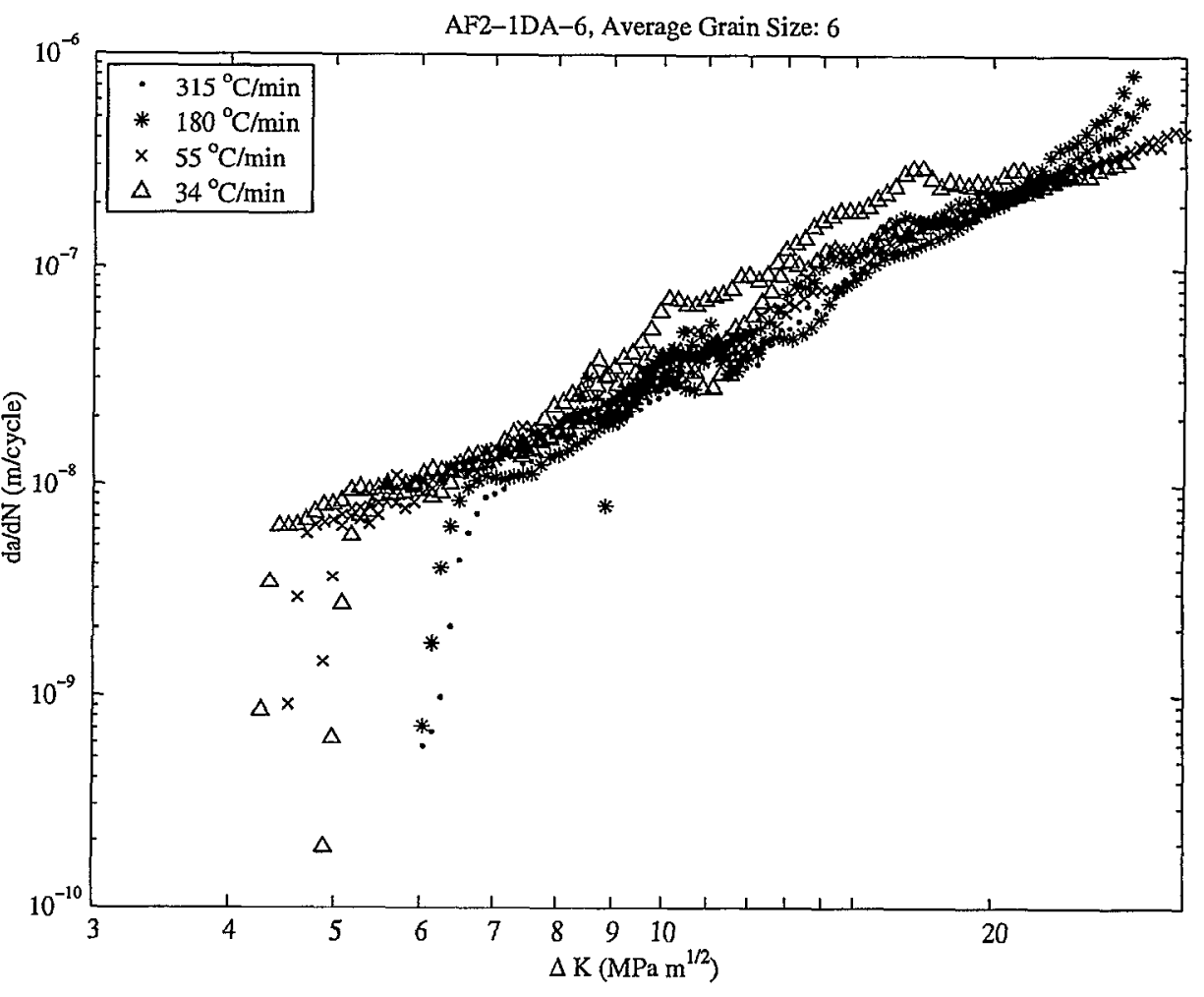

Figure 5. Fatigue crack propagation rates in AF2-1DA-6 tested at $1200 \mathrm{~F}$ with sinusoidal load at $10 \mathrm{~Hz}$ and $\mathrm{R}=0.7$. 


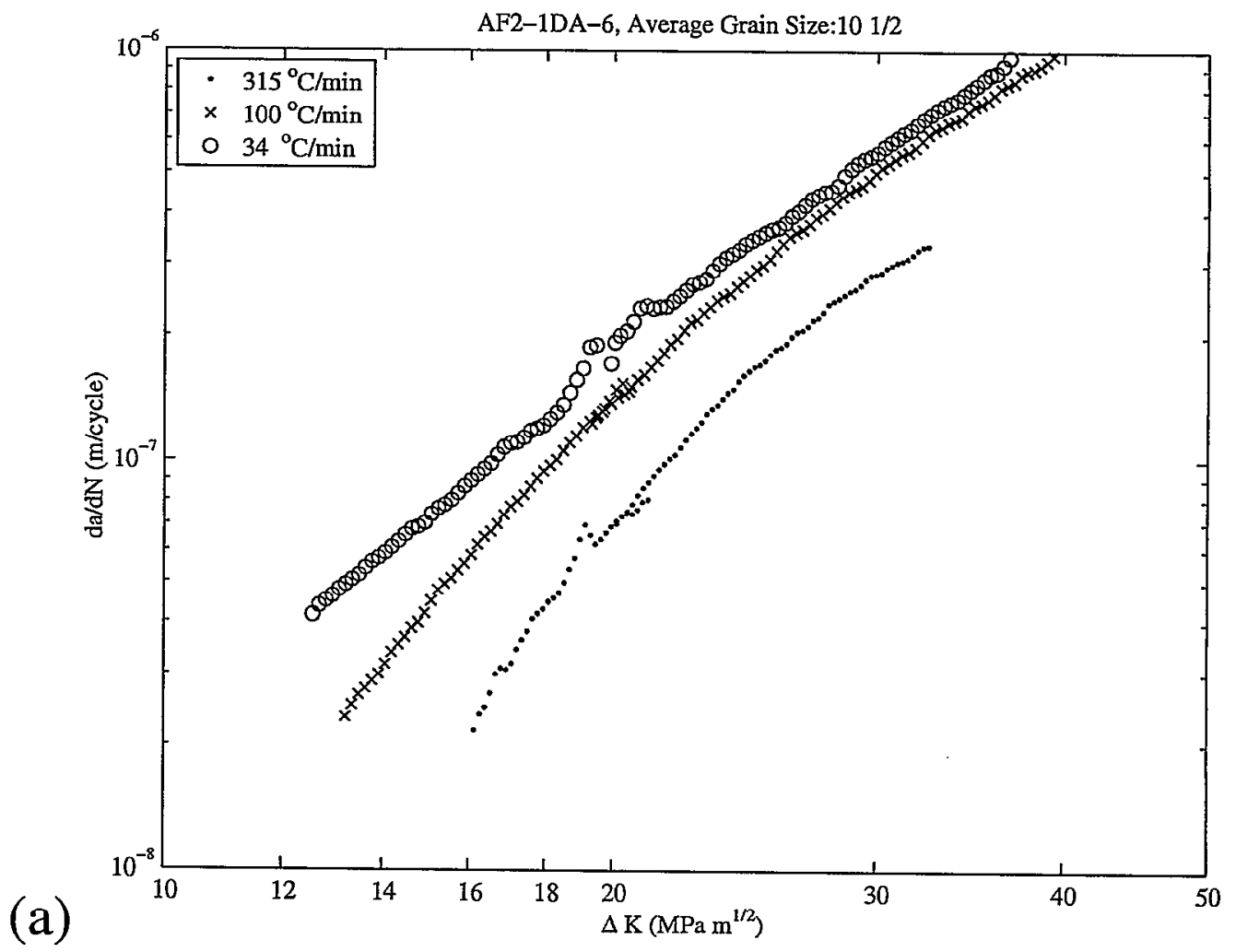

(a)

(b)

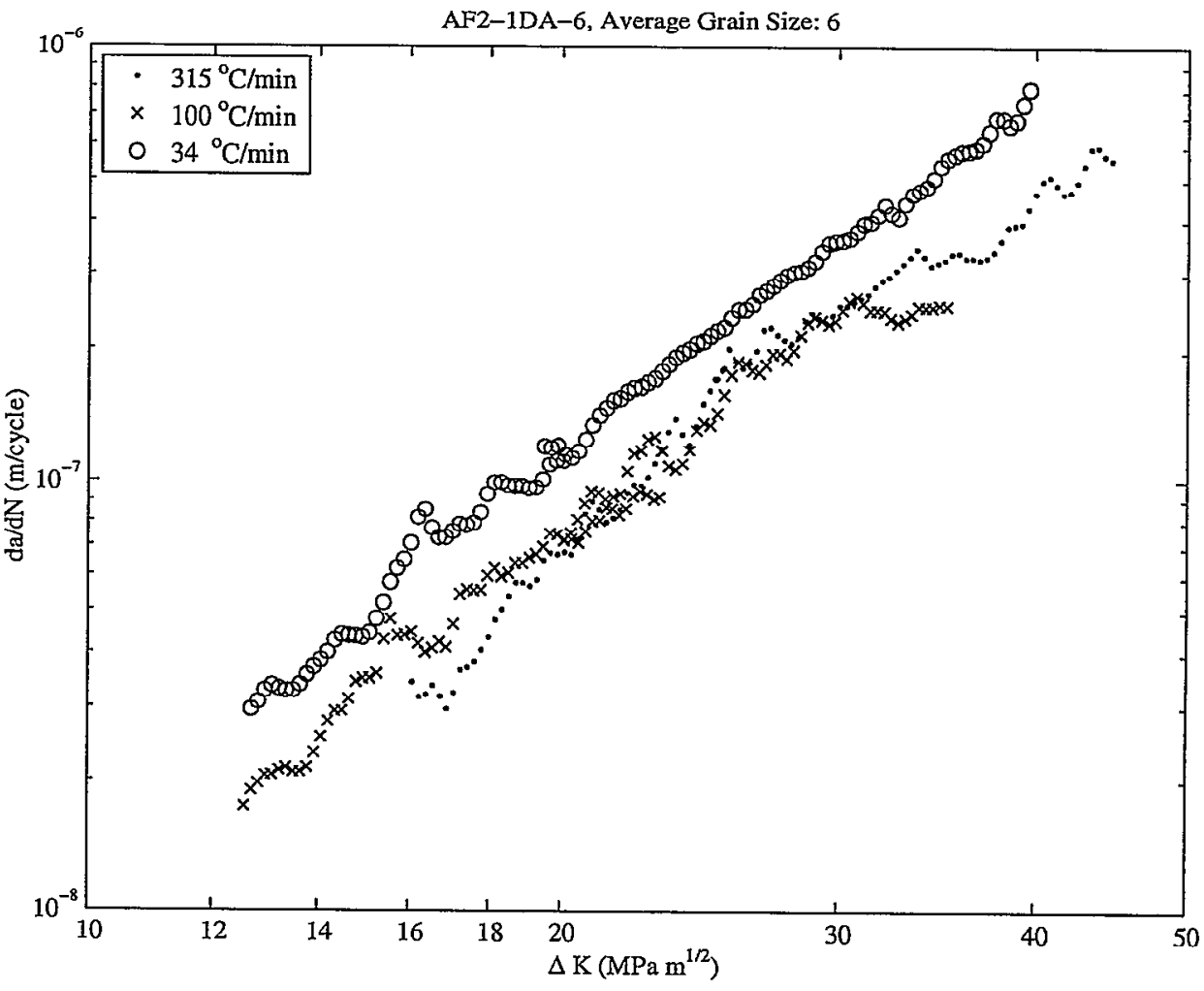

Figure 6. Fatigue crack propagation rates in AF2-1DA-6 tested at $1200 \mathrm{~F}$ with sinusoidal load at $2 \mathrm{~Hz}$ and $\mathrm{R}=0.05$. 